Available online on 15.10.2020 at http://jddtonline.info
Open Access to Pharmaceutical and Medical Research
unrestricted non-commercial use, provided the original work is properly cited

Open Access

Research Article

\title{
Comparative Non-Randomised Observational Study of Prasugrel and Ticagrelor in Patients Undergoing Percutaneous Coronary Intervention
}

\author{
Samala Sai Keerthana1*, Vaddepally Shravya1, Bandi Divya1, Subash Chandra Bose², A. Srinivasa Rao ${ }^{3}$ \\ 1-Pharm.D (Doctor of Pharmacy), Department of Pharmacy Practice, Bhaskar Pharmacy College, Moinabad, Hyderabad, Telangana, India \\ 2- Senior Consultant, Department of Cardiology, Apollo Hospitals, Jubilee Hills, Hyderabad- 500033, India
}

3-M. Pharm, Ph.D., F.I.C, Principal, Bhaskar Pharmacy College, Moinabad, Hyderabad, 500075, India

\begin{abstract}
Percutaneous Coronary Intervention (PCI) is the primary guideline-recommended treatment strategy for patients presenting with CAD, STEMI, NSTEMI, Unstable Angina. It is known that, the use of oral P2Y12 receptor antagonists (Prasugrel and Ticagrelor) in PCI patients could lead to improved outcomes compared with clopidogrel. This study has been designed for review and analysis of clinical safety and outcomes of these agents in patients undergoing PCI. Out of 100 patients (50 in Prasugrel group \& 50 in Ticagrelor group) considered for the study, the incidence of stroke, stent thrombosis was comparable between the groups with $\mathrm{P}=0.044, \mathrm{P}=0.041$ respectively and was not comparable for $\mathrm{MI}$ $(\mathrm{P}=0.245)$. Single Death was reported. The results differed significantly for Palpitations/Arrhythmia $(\mathrm{P}=0.018), \quad \mathrm{SOB}(\mathrm{P}=0.000)$, Dizziness $(\mathrm{P}=0.005)$, Creatinine levels $(\mathrm{P}=0.000)$, Fatigue $(\mathrm{P}=0.003)$, Headache $(\mathrm{P}=0.000)$ and did not differ significantly for Bleeding and $\mathrm{B}$ ack pain in both the drug groups with $\mathrm{P}=1.000, \mathrm{P}=0.438$ respectively. Also, majority of the patients showed decreased platelet count in both the drug groups. Withdrawal parameters, like withdrawal due to $\operatorname{cost}(\mathrm{P}=0.172)$ and withdrawal due to fear of side effects $(\mathrm{P}=1.000)$ when evaluated for both the drugs showed no significant difference. Outcomes associated with Prasugrel were not superior to outcomes associated with Ticagrelor when 30 days to 6 months follow up was done. The clinical safety, side effects and withdrawal parameters were comp arable and the results showed no significant difference between these drug groups.
\end{abstract}

Keywords: Percutaneous Coronary Intervention, Ticagrelor, Prasugrel, Dual Anti-Platelet therapy, Acute Coronary Syndrome, Coronary Artery Disease.

Article Info: Received 09 Aug 2020; $\quad$ Review Completed 13 Sep 2020; $\quad$ Accepted 22 Sep 2020; $\quad$ Available online 15 Oct 2020

Cite this article as:

Keerthana SS, Shravya V, Divya B, Bose SC, Rao AS, Comparative Non-Randomised Observational Study of Prasugrel and Ticagrelor in Patients Undergoing Percutaneous Coronary Intervention, Journal of Drug Delivery and Therapeutics. 2020; 10(5-s):57-63 http://dx.doi.org/10.22270/jddt.v10i5-s.4338

*Address for Correspondence:

Samala Sai Keerthana, Pharm.D (Doctor of Pharmacy), Department of Pharmacy Practice, Bhaskar Pharmacy College, Moinabad, Hyderabad, Telangana, India

\section{INTRODUCTION:}

High mortality rate in Indian population (range, $2.1 \%-6.7 \%$ ), is due to Acute Coronary Syndrome which has become an overburden. ${ }^{1}$ Another reason for the high mortality rate is Coronary Artery Disease. The treatment guidelines for patients with ACS and CAD is the dual antiplatelet therapy (DAPT). ${ }^{2}$ The recent guidelines of the American College of Cardiology/American Heart Association (ACC/AHA) and European Society of Cardiology (ESC) recommended the use of the newer P2Y12 inhibitors (Ticagrelor and Prasugrel) over Clopidogrel for patients with ACS undergoing PCI.3,4 Compared with placebo, recurrent major adverse cardiovascular events (MACE) have been reduced among patients with stable Coronary Artery Disease or Acute Coronary Syndrome (ACS) with dual antiplatelet therapy. ${ }^{5}$ The dual antiplatelet therapy is the combination of Aspirin along with an Adenosine diphosphate receptor antagonist. Greater and more rapid platelet inhibition is provided by the third generation thienopyridine Prasugrel and the cyclopentyltriazolopyrimidine Ticagrelor than their antecedent clopidogrel. ${ }^{6}$ After Percutaneous Coronary Intervention or Acute Coronary Syndrome, there was a considerable reduction in the risk of thrombotic events in patients who received dual antiplatelet therapy, but it has been associated with an increased risk of major bleeding. ${ }^{7}$

To date, there are few randomized clinical trial data directly comparing the safe and efficacy of Prasugrel with Ticagrelor. With the exception that Prasugrel may be better at reducing stent thrombosis, no apparent difference in major bleeding, the indirect comparisons showed no significant efficacy differences between the two drugs. ${ }^{8}$ There are also few nonrandomized trial data on this study which also showed no 
significant difference between these two drugs. Based on the patient clinical presentation, baseline risk profile and management strategy, the choice of IDEAL DAPT regimen and duration for patients with CAD requires a customized approach. ${ }^{9}$

This study was undertaken as a non-randomized, prospective, observational study to compare the efficacy and safety of Prasugrel and Ticagrelor in patients undergoing Percutaneous Coronary Intervention and 30 days to 6 months follow-up was done succeeding the treatment.

\section{Objectives:}

- $\quad$ To observe the major adverse clinical outcomes during index hospitalization in 1 month after discharge.

- $\quad$ To access the safety and side effects of these drugs by using BARC (Bleeding Academic Research Consortium) Criteria for bleeding.

\section{MATERIALS AND METHODS:}

Study Design: A hospital based Prospective, Nonrandomized Observational Study.

\section{Study Site and Study Period:}

This study was conducted for 6 months (i.e. September 2019 - February 2020) in Asia's first health city, Apollo Hospitals, Jubilee Hills, Hyderabad.

\section{Sample Size:}

The total numbers of patients included in this study are 100. Out of which, 50 patients were using Ticagrelor and 50 patients were using Prasugrel.

\section{Method of Data Collection:}

Subjects enrolled in the study were admitted in CICU and CSICU. Informed consent was obtained from all the subjects. The disease condition was evaluated after obtaining consent from each of them. Patient details including demographics, chief complaints, past medical history, family history, other comorbidities, physical examination, laboratory investigations, contact details and other relevant information has been collected from case reports. The patients who revisited the outpatient department of Cardiology, Apollo Hospitals were examined for side effects and clinical outcomes. The obtained clinical data and the results were reexamined and entered in the data collection forms and further results obtained were tabulated and graphs were plotted.

\section{Inclusion Criteria:}

- $\quad$ Patients of age $>18$ years

- Patients who are conscious and co-operative.

- Patients who received Elective (or) Emergent PCI and are on medications-Ticagrelor/Prasugrel.

- Includes patients of both the gender.

- Patients who are willing to give information.

\section{Exclusion Criteria:}

- Patients who are not conscious, not co-operative and who cannot communicate verbally are excluded.

- Patients in cardiogenic shock.

- Patient with known bleeding diathesis.

- Patient with allergic/hypersensitivity to drug.

- Patient undergoing PABG (Penile Artery By-pass surgery).

\section{Statistical Analysis:}

Microsoft Office, Word 2010 and excel 2019 were used to produce the results in the form of charts and percentages.

SPSS Statistics Software (Version 1.0.0.86, Trial version) was used for statistical analysis with $P$ value $\leq 0.05$. Multivariate analysis was used to compare Primary endpoints, Secondary endpoints and withdrawal parameters whereas Paired t-test was used to compare the platelet count before and after the medication use.

Ethical Committee Approval No: AHJ-028/10-19

\section{RESULTS:}

\section{Patients Baseline Characteristics:}

A total of 100 patients were enrolled in this study ( $n=50$ in Prasugrel group and $n=50$ in Ticagrelor group). The entire baseline Demographics i.e. Sex, Age, Body Mass Index, Diagnosis along with the different Clinical laboratory tests i.e. Left Ventricular dysfunction and Angiographic lesion severity in two treatment groups are considered (Table-1). 
TABLE 1: BASELINE CHARACTERISTICS OF PATIENTS WHO UNDERWENT PERCUTANEOUS CORONARY INTERVENTION $(\mathrm{N}=100)$

\begin{tabular}{|c|c|c|}
\hline Parameters & $\begin{array}{c}\text { Ticagrelor } \\
(n=50)\end{array}$ & $\begin{array}{c}\text { Prasugrel } \\
(n=50)\end{array}$ \\
\hline \multicolumn{3}{|l|}{ Sex n, (\%) } \\
\hline Male & $35(70 \%)$ & $38(76 \%)$ \\
\hline Female & $15(30 \%)$ & $12(24 \%)$ \\
\hline \multicolumn{3}{|l|}{ Age n, (\%) } \\
\hline Early adulthood (19-35) & $0(0 \%)$ & $1(2 \%)$ \\
\hline Adulthood (36-50) & $10(20 \%)$ & $20(40 \%)$ \\
\hline Late adulthood (51-65) & $24(48 \%)$ & $24(48 \%)$ \\
\hline Young old (66-74) & $14(28 \%)$ & $5(10 \%)$ \\
\hline Old (75-84) & $2(4 \%)$ & $0(0 \%)$ \\
\hline Old-old (>85) & $0(0 \%)$ & $0(0 \%)$ \\
\hline \multicolumn{3}{|l|}{ BMI n, (\%) } \\
\hline Under weight $(<18.5)$ & $0(0 \%)$ & $1(2 \%)$ \\
\hline Healthy (18.5-24.9) & $16(32 \%)$ & $14(28 \%)$ \\
\hline Overweight (25-29.9) & $18(36 \%)$ & $22(44 \%)$ \\
\hline Obese $(>30)$ & $16(32 \%)$ & $13(26 \%)$ \\
\hline \multicolumn{3}{|l|}{ LV dysfunction $\mathrm{n},(\%)$} \\
\hline Normal & $23(46 \%)$ & $17(34 \%)$ \\
\hline Mild & $19(38 \%)$ & $21(42 \%)$ \\
\hline Moderate & $2(4 \%)$ & $7(14 \%)$ \\
\hline Severe & $6(12 \%)$ & $5(10 \%)$ \\
\hline \multicolumn{3}{|c|}{ Angiographic lesion severity n, (\%) } \\
\hline Single vessel disease & $24(48 \%)$ & $29(58 \%)$ \\
\hline Double vessel disease & $12(24 \%)$ & $14(28 \%)$ \\
\hline Triple vessel disease & $14(28 \%)$ & $7(14 \%)$ \\
\hline \multicolumn{3}{|l|}{ Diagnosis n, (\%) } \\
\hline Unstable angina & $18(36 \%)$ & $14(28 \%)$ \\
\hline STEMI & $18(36 \%)$ & $16(32 \%)$ \\
\hline NSTEMI & $14(28 \%)$ & $20(40 \%)$ \\
\hline
\end{tabular}

BMI - Body Mass Index, LV - Left Ventricular, STEMI - ST-segment Elevation Myocardial Infarction, NSTEMI - Non-STsegment Elevation Myocardial Infarction.

\section{Primary Endpoints:}

The primary endpoints did not differ significantly in both the drug groups for Myocardial Infarction ( $P>0.05$ ), whereas it differed significantly in case of Stroke, Stent thrombosis and Death $(P<0.05)$. The respective results for all the parameters are illustrated in Table- 2 and corresponding graph is plotted (Figure-1).

TABLE 2: INTERGROUP COMPARISON OF PRIMARY ENDPOINTS

\begin{tabular}{|l|c|c|c|}
\hline Primary endpoints & $\begin{array}{c}\text { Ticagrelor } \\
\text { n (\%) }\end{array}$ & $\begin{array}{c}\text { Prasugrel } \\
\text { n (\%) }\end{array}$ & $\begin{array}{c}\text { P-value } \\
\text { (intergroup) }\end{array}$ \\
\hline 1.No endpoints & $44(88 \%)$ & $47(94 \%)$ & $0.245(\mathrm{NS})$ \\
\hline 2.MI & $2(4 \%)$ & $1(2 \%)$ & $0.044(\mathrm{~S})$ \\
\hline 3.Stroke & 0 & $1(2 \%)$ & $0.041(\mathrm{~S})$ \\
\hline 4.Stent thrombosis & $3(6 \%)$ & $1(2 \%)$ & $0.044(\mathrm{~S})$ \\
\hline 5.Death & $1(2 \%)$ & 0 & \\
\hline
\end{tabular}

NS - Non-Significant, S - Significant. Significance level, $\alpha=0.05$ 


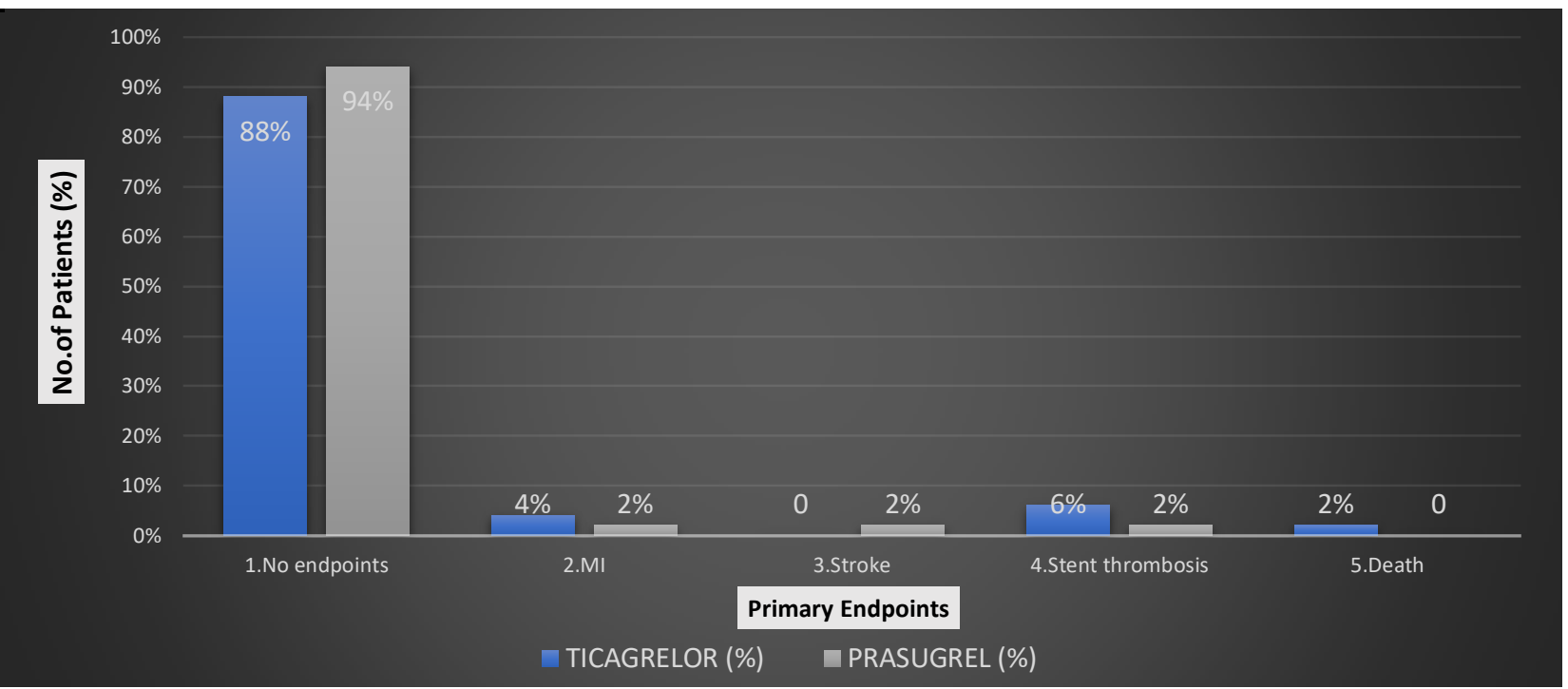

Figure 1: Comparison of primary endpoints (in \%)

\section{Secondary Endpoints:}

The secondary endpoints differ significantly for Palpitations/Arrhythmia, SOB, Dizziness, Creatinine levels,
Fatigue, Headache $(\mathrm{P}<0.05)$ and did not differ significantly for Bleeding and Back pain in both the groups $(\mathrm{P}>0.05)$ which are demonstrated in detail in Table-3 and the respective graph is plotted (Figure-2).

TABLE 3: INTERGROUP COMPARISON OF SECONDARY ENDPOINTS.

\begin{tabular}{|l|l|l|l|}
\hline Safety endpoints & $\begin{array}{l}\text { Ticagrelor } \\
\text { n (\%) }\end{array}$ & $\begin{array}{l}\text { Prasugrel } \\
\text { n (\%) }\end{array}$ & $\begin{array}{l}\text { P-value } \\
\text { (intergroup) }\end{array}$ \\
\hline 1.No endpoints & $21(42 \%)$ & $20(40 \%)$ & \\
\hline 2.Palpitations/Arrhythmia & $2(4 \%)$ & $5(10 \%)$ & $0.018(\mathrm{~S})$ \\
\hline 3.SOB & $10(20 \%)$ & $3(6 \%)$ & $0.000(\mathrm{~S})$ \\
\hline 4.Creatinine Raised & $5(10 \%)$ & 0 & $0.000(\mathrm{~S})$ \\
\hline 5.Dizziness & $4(8 \%)$ & $1(2 \%)$ & $0.005(\mathrm{~S})$ \\
\hline 6.Back Pain & $3(6 \%)$ & $4(8 \%)$ & $0.438(\mathrm{NS})$ \\
\hline 7.Fatigue & $2(4 \%)$ & $6(12 \%)$ & $0.003(\mathrm{~S})$ \\
\hline 8.Headache & 0 & $8(16 \%)$ & $0.000(\mathrm{~S})$ \\
\hline 9.Bleeding & $3(6 \%)$ & $3(6 \%)$ & $1.000(\mathrm{NS})$ \\
\hline
\end{tabular}

NS - Non-Significant, S - Significant. Significance level, $\alpha=0.05$

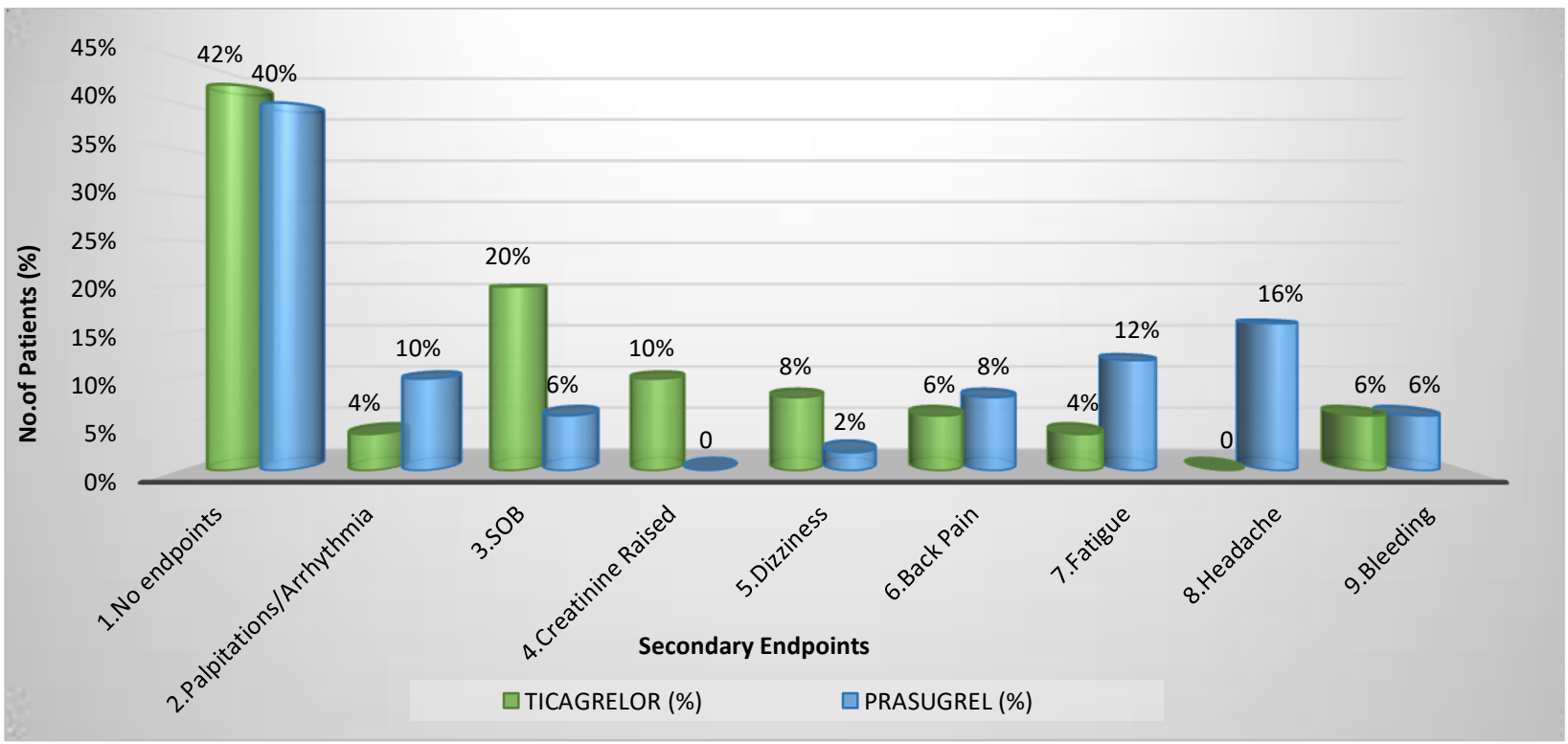

Figure 2: Comparison of Secondary Endpoints (in \%). 


\section{Withdrawal Parameters:}

The withdrawal parameters did not differ significantly in both the drug groups $(\mathrm{P}>0.05)$ that are illustrated in Table- 4 and is also graphically represented (Figure-3).

TABLE 4: COMPARISON OF WITHDRAWAL PARAMETERS.

\begin{tabular}{|l|c|c|c|}
\hline Parameter & $\begin{array}{c}\text { Ticagrelor } \\
\mathbf{n = 5 0}\end{array}$ & $\begin{array}{c}\text { Prasugrel } \\
\mathbf{n = 5 0}\end{array}$ & $\begin{array}{c}\text { P-value } \\
\text { (Intergroup) }\end{array}$ \\
\hline 1.No withdrawal & $44(88 \%)$ & $47(94 \%)$ & $0.172(\mathrm{NS})$ \\
\hline 2.Due to cost & $4(8 \%)$ & $1(2 \%)$ & $1.000(\mathrm{NS})$ \\
\hline 3.Due to fear of side effects & $2(4 \%)$ & $2(4 \%)$ & \\
\hline
\end{tabular}

NS - Non-Significant, $\quad$ Significance level, $\alpha=0.05$

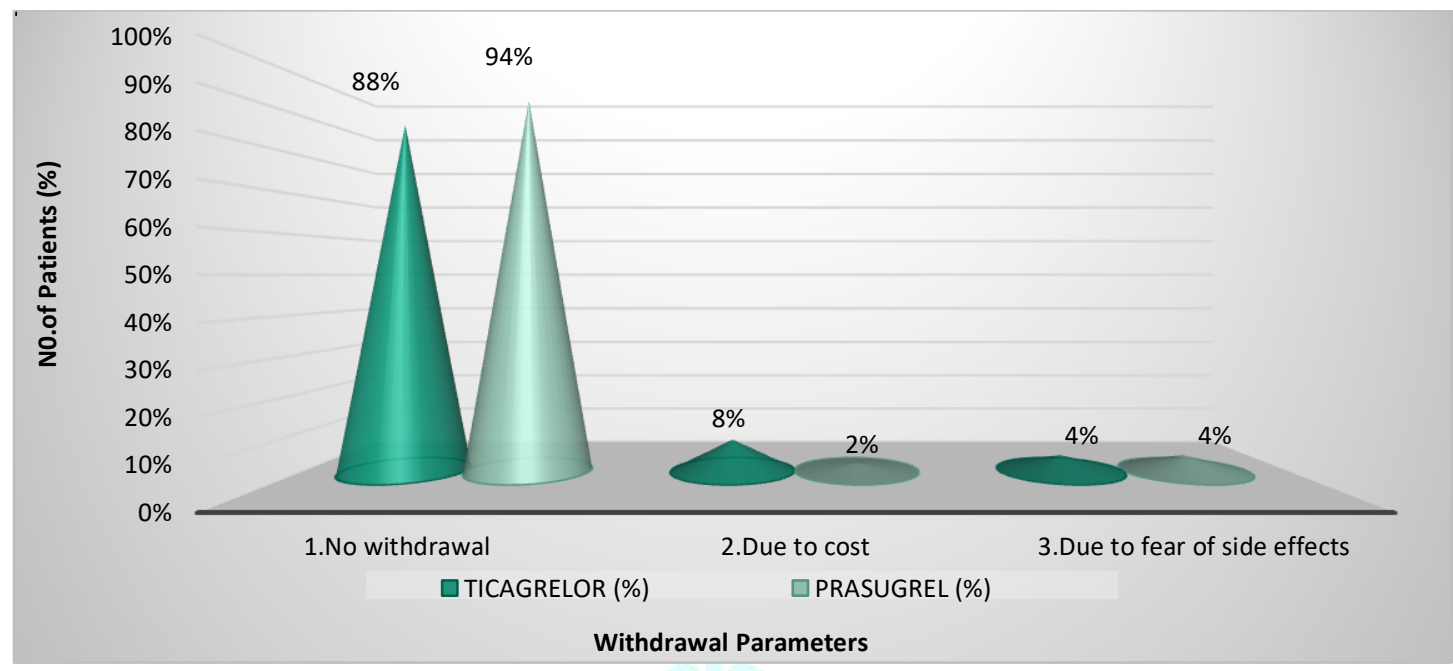

Figure 3: Comparison of Withdrawal Parameters (in \%).

\section{Platelet count before and after the use of Anti-Platelet} medications:

Platelet count is one of the factors that relates directly to the efficacy of Anti-platelet medications. Statistical analysis was made using Paired t-test at Confidence Interval of $95 \%$ (Table 5). The platelet count was decreased from 292.34 (Mean of the platelet count before use of medications) to 239.60 (Mean of the platelet count after the use of medications).

TABLE 5: PLATELET COUNT BEFORE AND AFTER PCI (I.E. USE OF ANTI-PLATELET MEDICATIONS).

\begin{tabular}{|c|c|c|c|c|c|c|c|c|c|}
\hline \multicolumn{10}{|c|}{ Paired Samples Test } \\
\hline & & \multicolumn{5}{|c|}{ Paired Differences } & \multirow[b]{3}{*}{$\mathrm{T}$} & \multirow[b]{3}{*}{$\mathrm{df}$} & \multirow[t]{3}{*}{$\begin{array}{l}\text { Sig. (2- } \\
\text { tailed) }\end{array}$} \\
\hline & & \multirow[b]{2}{*}{ Mean } & \multirow{2}{*}{$\begin{array}{c}\text { Std. } \\
\text { Deviation }\end{array}$} & \multirow{2}{*}{$\begin{array}{l}\text { Std. Error } \\
\text { Mean }\end{array}$} & \multicolumn{2}{|c|}{$\begin{array}{l}\text { 95\% Confidence Interval } \\
\text { of the Difference }\end{array}$} & & & \\
\hline & & & & & Lower & Upper & & & \\
\hline$\overline{\text { Pair } 1}$ & $\begin{array}{l}\text { Platelets before PCI - } \\
\text { Platelets after PCI }\end{array}$ & 52.74000 & 65.90177 & 6.59018 & 39.66366 & 65.81634 & 8.003 & 99 & .000 \\
\hline
\end{tabular}

Significance level, $\alpha=0.05$, Confidence Interval $-95 \%$

\section{DISCUSSION:}

Percutaneous coronary intervention (PCI) is the primary guideline-recommended treatment strategy for patients presenting with CAD, STEMI, NSTEMI, Unstable Angina. ${ }^{10}$ For patients diagnosed with $\mathrm{CAD}$ and undergoing Percutaneous Coronary Intervention (PCI), newer oral
P2Y12 receptor antagonists (i.e. Prasugrel and Ticagrelor) are recommended over clopidogrel.11,12 Following PCI, the adverse events associated were reduced with the addition of oral platelet P2Y12 ADP receptor inhibitors along with Aspirin. Therefore, dual-antiplatelet therapy (DAPT) in PCI patients has been recommended for use before and after the procedure for a minimum period of $6-12$ months. ${ }^{13}$ As the 
superiority of one agent over the other remains unclear in Indian population, research has been ongoing for further evaluation of these drugs.

This prospective, non-randomised observational study has been designed for review and analysis of these agents (Prasugrel and Ticagrelor) in patients undergoing PCI. The findings obtained from this study may recommend that the use of either Prasugrel or Ticagrelor in PCI patients could lead to improved outcomes.

The comparative effectiveness and safety evaluation between prasugrel and ticagrelor were presented in this observational study. Primary end points include Myocardial Infarction (MI), Stroke, Stent Thrombosis and Death whereas the Secondary end points include Palpitation/Arrhythmia, SOB, Dizziness, Creatinine levels, Fatigue, Headache, Back pain and Bleeding.

In this Prospective Non-randomized Observational study, a total of 100 patients were considered in the ratio of $1: 1$ (Ticagrelor and Prasugrel). Out of 100 patients, males were found to be dominant ${ }^{14}$ (70\% in Ticagrelor group \& $76 \%$ in Prasugrel group) compared to females (30\% in Ticagrelor group \& 24\% in Prasugrel group).

The total population was divided into different age groups according to the WHO guidelines i.e., early adulthood (1935years), adulthood (36 - 50years), late adulthood (51 65 years), young old (66 - 74years), old (75 - 84years), oldold ( $>$ 85years). Most of the patients using these two drugs were found to be in late adulthood ${ }^{15}$ (48\% in Ticagrelor group \& 48\% in Prasugrel group).

The total population was distributed based on BMI into different groups ${ }^{16}$ i.e., Underweight $(<18.5)$, Healthy (18.5$24.9)$, Over weight (25.0-29.9), Obese ( $>30)$. Distribution of patients that were found to be in Healthy group are $32 \%$ in Ticagrelor \& $28 \%$ in Prasugrel), Over weight $36 \%$ in Ticagrelor \& 44\% in Prasugrel), Obese (32\% in Ticagrelor \& $26 \%$ in Prasugrel).

According to the study conducted, the patients were found to be diagnosed with CAD, STEMI, NSTEMI, Unstable Angina. ${ }^{8}$

Based on the 2D- ECHO results, we considered LV function of the patients 17 and divided into categories of Normal(46\% of patients in Ticagrelor \& $34 \%$ of patients in Prasugrel), Mild(38\% of patients in Ticagrelor \& $42 \%$ of patients in Prasugrel), Moderate(4\% of patients in Ticagrelor \& $14 \%$ of patients in Prasugrel) and Severe $(12 \%$ of patients in Ticagrelor $\& 10 \%$ of patients in Prasugrel).

The patients are further divided based on the number of vessels involved. Patients with single vessel disease were found to be $48 \%$ in Ticagrelor group \& $58 \%$ in Prasugrel group, double vessel disease were found to be $24 \%$ in Ticagrelor group \& 28\% in Prasugrel group and triple vessel disease were found to be $28 \%$ in Ticagrelor group \& $14 \%$ in Prasugrel group. Thus, most of patients were found to be having Single Vessel Disease. ${ }^{18}$

This study reported that prasugrel and ticagrelor did not differ significantly for their clinical efficacy. Clinical Safety and Tolerance were comparable in both the groups in patients who underwent PCI at the end of 6 months. ${ }^{1}$

In this study Stent Thrombosis was comparable between both the groups ${ }^{1}$, with $3(6 \%)$ patients in Ticagrelor group and $1(2 \%)$ patient in Prasugrel group. Based on the statistical tests applied for this parameter, the p-value was found to be non-significant. Therefore, there is no significant difference in both these drug groups.
Prasugrel group reported less MI events compared to Ticagrelor group i.e., ( $2 \%$ and $4 \%$ respectively). Prasugrel group were found with $2 \%$ of stroke cases \& no cases were found in Ticagrelor group. Single Death case was reported in Ticagrelor group.

One of the factors that directly relates to the efficacy of ticagrelor and prasugrel is the platelet count. Majority of the patients showed decreased platelet count in both the drug groups. ${ }^{19}$ The results showed significant difference in the platelet count when paired ' $\mathrm{t}$ ' test method was used statistically.

In the Intergroup Comparision of ticagrelor and prasugrel, the secondary endpoints showed the following results. Overall, Backpain and Bleeding showed no significant difference between these two drug groups at 6-months follow-up. 6

Palpitations/Arrhythmia was found in 2 patients of Ticagrelor group and 5 patients in Prasugrel group. 6

Shortness of breath was not frequently reported in prasugrel group when compared to Ticagrelor group. Higher rate of incidence of SOB was found in Ticagrelor group. ${ }^{20}$

In other secondary endpoints like, Dizziness, Creatinine levels, Fatigue and Headache showed significant difference between these two drug groups when multivariant statistical method was applied. 6

Both Prasugrel and Ticagrelor have been approved by ICP (International Clinical Practice) Guidelines for the prevention of Secondary thrombotic events in patients with ACS. However, there is a difference in the cost of these drugs. India has been able to lift a significant percentage of its population out of poverty, but many still live in it. So, there is a chance of withdrawal of the drug by the subjects since they may not be able to afford for the treatment. Also, the drug usage may be discontinued by few because of the unusual effects caused by them after using for a particular period of time. Considering this situation of Indian population, withdrawal parameters i.e. withdrawal due to cost and withdrawal due to fear of side effects are included in this study. The results obtained from these two parameters, showed no significant difference between these two drug groups. ${ }^{21}$

\section{CONCLUSION:}

Overall, the Comparision of efficacy and safety of Ticagrelor and Prasugrel in patients undergoing PCI showed minimal differences in both drug groups because of the low sample size considered. Thus, we conclude that both the Antiplatelet drugs are equally efficacious.

\section{ACKNOWLEDGMENT:}

We offer our heartfelt thanks to Dr. Subash Chandra Bose, MBBS, MD, DM (Cardiology), Apollo Hospitals, Dr. A.

Srinivasa Rao, M. Pharm, Ph.D., F.I.C, Principal, Bhaskar Pharmacy College and Dr. Syed Mushtaq, M. Pharm, Ph. D (Pharmacology) for their worthy support, cooperation and time in providing the needed information that served as the major contribution towards the completion of this study.

Conflict of interest: There are no conflicts of interests.

\section{REFERENCES:}

1. Bhatia R, Chaudhari N, Dugal JS, Mehta AC. Prasugrel versus ticagrelor in Indian patients with acute coronary syndrome undergoing percutaneous coronary intervention: A prospective, randomized, comparative study. Indian Heart Journal Interventions. 2018 May 1; 1(2):136. 
2. Kumar A, Cannon CP. Acute coronary syndromes: diagnosis and management, part I. InMayo Clinic Proceedings 2009; 84(10):917-938. Elsevier.

3. Watti H, Dahal K, Zabher HG, Katikaneni P, Modi K, Abdulbaki A. Comparison of prasugrel and ticagrelor in patients with acute coronary syndrome undergoing percutaneous coronary intervention: A meta-analysis of randomized and nonrandomized studies. International journal of cardiology. 2017 Dec 15; 249:66-72.

4. Sakurai R, Burazor I, Bonneau HN, Kaneda H. Head-to-head comparison of prasugrel versus ticagrelor in patients undergoing percutaneous coronary intervention: A metaanalysis of randomized controlled trials. Journal of interventional cardiology. 2017 Oct; 30(5):457-64.

5. Schmucker J, Fach A, Mata Marin LA, Retzlaff T, Osteresch R, Kollhorst B, Hambrecht R, Pohlabeln H, Wienbergen $\mathrm{H}$. Efficacy and Safety of Ticagrelor in Comparison to Clopidogrel in Elderly Patients With ST-Segment-Elevation Myocardial Infarctions. Journal of the American Heart Association. 2019 Sep 17; 8(18): e012530.

6. Schüpke S, Neumann FJ, Menichelli M, Mayer K, Bernlochner I, Wöhrle J, Richardt G, Liebetrau C, Witzenbichler B, Antoniucci D, Akin I. Ticagrelor or prasugrel in patients with acute coronary syndromes. New England Journal of Medicine. 2019 Oct 17; 381(16):1524-34.

7. Giri J, Nathan A. Is it Time to Abandon Dual Antiplatelet Therapy After Percutaneous Coronary Intervention in Patients with Atrial Fibrillation on Anticoagulation?

8. Larmore C, Effron MB, Molife C, DeKoven M, Zhu Y, Lu J, Karkare S, Lieu HD, Lee WC, Vetrovec GW. "Real-world" comparison of prasugrel with ticagrelor in patients with acute coronary syndrome treated with percutaneous coronary intervention in the United States. Catheterization and Cardiovascular Interventions. 2016 Oct; 88(4):535-44.

9. Degrauwe S, Pilgrim T, Aminian A, Noble S, Meier P, Iglesias JF. Dual antiplatelet therapy for secondary prevention of coronary artery disease. Open heart. 2017 Oct 1; 4(2): e000651.

10. Smith Jr SC, Dove JT, Jacobs AK, Kennedy JW, Kereiakes D, Kern MJ, Kuntz RE, Popma JJ, Schaff HV, Williams DO, Gibbons RJ. ACC/AHA guidelines for percutaneous coronary intervention (revision of the 1993 PTCA guidelines)executive summary: a report of the American College of Cardiology/American Heart Association task force on practice guidelines (Committee to revise the 1993 guidelines for percutaneous transluminal coronary angioplasty) endorsed by the Society for Cardiac Angiography and Interventions. Circulation. 2001 Jun 19; 103(24):3019-41.

11. Bednar F, Kroupa J, Ondrakova M, Osmancik P, Kopa M, Motovska Z. Antiplatelet efficacy of P2Y 12 inhibitors (prasugrel, ticagrelor, clopidogrel) in patients treated with mild therapeutic hypothermia after cardiac arrest due to acute myocardial infarction. Journal of thrombosis and thrombolysis. 2016 May 1; 41(4):549-55.
12. Motovska Z, Hlinomaz O, Miklik R, Hromadka M, Varvarovsky I, Dusek J, Knot J, Jarkovsky J, Kala P, Rokyta R, Tousek F. Prasugrel versus ticagrelor in patients with acute myocardial infarction treated with primary percutaneous coronary intervention: multicentre randomized PRAGUE-18 study. Circulation. 2016 Nov 22; 134(21):1603-12.

13. Saito Y, Kobayashi Y. Update on antithrombotic therapy after percutaneous coronary intervention. Internal Medicine. 2020 Feb 1; 59(3):311-21.

14. Kumar V, Kumar V, Kumari K, Talwar KK, Prasad D, Agarwal S, Yadav MS, Bashir H, Jatain S, Gupta SK. Clinical safety profile of ticagrelor compared to clopidogrel in 1208 patients: Real world evidence. The Egyptian Heart Journal. 2018 Dec 1; 70(4):375-8.

15. Parodi G, Valenti R, Bellandi B, Migliorini A, Marcucci R, Comito V, Carrabba N, Santini A, Gensini GF, Abbate R, Antoniucci D. Comparison of prasugrel and ticagrelor loading doses in ST-segment elevation myocardial infarction patients: RAPID (Rapid Activity of Platelet Inhibitor Drugs) primary PCI study. Journal of the American College of Cardiology. 2013 Apr 16; 61(15):1601-6.

16. Ahn KT, Seong SW, Choi UL, Jin SA, Kim JH, Lee JH, Choi SW, Jeong MH, Chae SC, Kim YJ, Kim CJ. Comparison of 1-year clinical outcomes between prasugrel and ticagrelor versus clopidogrel in type 2 diabetes patients with acute myocardial infarction underwent successful percutaneous coronary intervention. Medicine. 2019 Mar; 98(11).

17. Franchi F, Rollini F, Aggarwal N, Hu J, Kureti M, Durairaj A, Duarte VE, Cho JR, Been L, Zenni MM, Bass TA. Pharmacodynamic comparison of prasugrel versus ticagrelor in patients with type 2 diabetes mellitus and coronary artery disease: the OPTIMUS (Optimizing Antiplatelet Therapy in Diabetes Mellitus)-4 study. Circulation. 2016 Sep 13; 134(11):780-92.

18. Park K, Cho YR, Park JS, Park TH, Kim MH, Kim YD. Design and rationale for comparison between ticagrelor and clopidogrel on microcirculation in patients with acute coronary syndrome undergoing percutaneous coronary intervention (PLEIO) trial. Journal of cardiovascular translational research. 2018 Feb 1; 11(1):42-9.

19. De Labriolle A, Bonello L, Lemesle G, Roy P, Steinberg DH, Xue Z, Suddath WO, Satler LF, Kent KM, Pichard AD, Lindsay J. Decline in platelet count in patients treated by percutaneous coronary intervention: definition, incidence, prognostic importance, and predictive factors. European heart journal. 2010 May 1; 31(9):1079-87.

20. Wallentin L, Becker RC, Budaj A, Cannon CP, Emanuelsson H, Held C, Horrow J, Husted S, James S, Katus H, Mahaffey KW. Ticagrelor versus clopidogrel in patients with acute coronary syndromes. New England Journal of Medicine. 2009 Sep 10; 361(11):1045-57.

21. Zhao YJ, Khoo AL, Lin L, Teng M, Wu TS, Chan MY, Lim BP. Cost-effectiveness analysis of ticagrelor and prasugrel for the treatment of acute coronary syndrome. Value in health regional issues. 2016 May 1; 9:22-7. 